\title{
Editorial
}

\section{Natural, Synthetic, and Recycled Polymers in Composite Materials}

\author{
Gonzalo Martínez-Barrera, ${ }^{1}$ Osman Gencel, ${ }^{2}$ \\ Carmina Menchaca-Campos, ${ }^{3}$ and Enrique Vigueras-Santiago ${ }^{1}$ \\ ${ }^{1}$ Laboratorio de Investigación y Desarrollo de Materiales Avanzados (LIDMA), Facultad de Química, \\ Universidad Autónoma del Estado de México, Km 12 de la Carretera Toluca-Atlacomulco, 50200 San Cayetano, MEX, Mexico \\ ${ }^{2}$ Civil Engineering Department, Faculty of Engineering, Bartin University, 74100 Bartin, Turkey \\ ${ }^{3}$ Centro de Investigación en Ingeniería y Ciencias Aplicadas (CIICAp), Universidad Autónoma del Estado de Morelos, \\ 62210 Cuernavaca, MOR, Mexico
}

Correspondence should be addressed to Gonzalo Martínez-Barrera; gonzomartinez02@yahoo.com.mx

Received 1 September 2013; Accepted 1 September 2013

Copyright ( 2013 Gonzalo Martínez-Barrera et al. This is an open access article distributed under the Creative Commons Attribution License, which permits unrestricted use, distribution, and reproduction in any medium, provided the original work is properly cited.

Mechanical and management improvements in composite materials require the use of new ways to produce them. The actual tendencies and global developments of novel materials include the introduction of natural, synthetic, and recycled polymers into the composite materials. Recently, composite materials have been used for certain applications, which depend on several conditions such as materials' nature, concentrations, and methodology for their elaboration. Nevertheless, certain properties are not reachable with traditional components; thus, different materials are needed as fillers for reinforce and improve such properties. A worldwide tendency is to use recycled or natural materials and evaluate their influence after adding them to the composite materials. In this sense, polymers are used in a very large variety of composite materials, mainly as fillers or reinforcements. Their chemical structure and physical morphology have been modified by using different kind of energies, including thermal, chemical, and radiation energy. The perspectives are to obtain new materials with improved properties at low cost by using easy technologies and chemically sustainable for the environment.

The knowledge and understanding of such composite materials are therefore of great importance for our living. In this issue, some investigations related to composite materials are shown, covering different topics, including improvement of the biocompatibility of polycaprolactone and silica aerogel composites used as tissue engineering scaffolds or modifications of polymers (polyphosphazenes) by using some chemicals; polymeric composites with electrical and dielectric properties, including polyaniline conductive compounds and $\mathrm{V}_{2} \mathrm{O}_{5}$, whose routes of synthesis are made in situ, where the energy band gap is controlled by the amount of particles; the outstanding use of recycled polyolefins for improvement of bitumen materials and recycled PET of water bottles and its use as filler material of concrete; polymer fibers as reinforcement of polymer composites, especially of polyester-based concretes; the use of recycling copolymers from the automotive industry and their conversion into corrosion protection coatings for metal artifact cultural heritage conservation purposes, highlighting their properties when comparing to a commercial varnish used in conservation. Moreover, the topics also include composite coatings manufactured by electrospinning method for applications in fuel cells, energy storage, and coatings against corrosion; control of the mechanical properties of polymer-cement composites, focusing on comparison of cement-based and polymer-based concrete pipes; natural rubber used in the porous asphalt mixtures, or tire rubber in the manufacture of 
biodegradable composites; studies of polymer/nanoparticles composites synthetized by facile solventless procedure; polymeric compounds derived from renewable sources for the detection of solvents, where detection sensitivity is controlled by the layer thickness.

Gonzalo Martínez-Barrera Osman Gencel Carmina Menchaca-Campos Enrique Vigueras-Santiago 

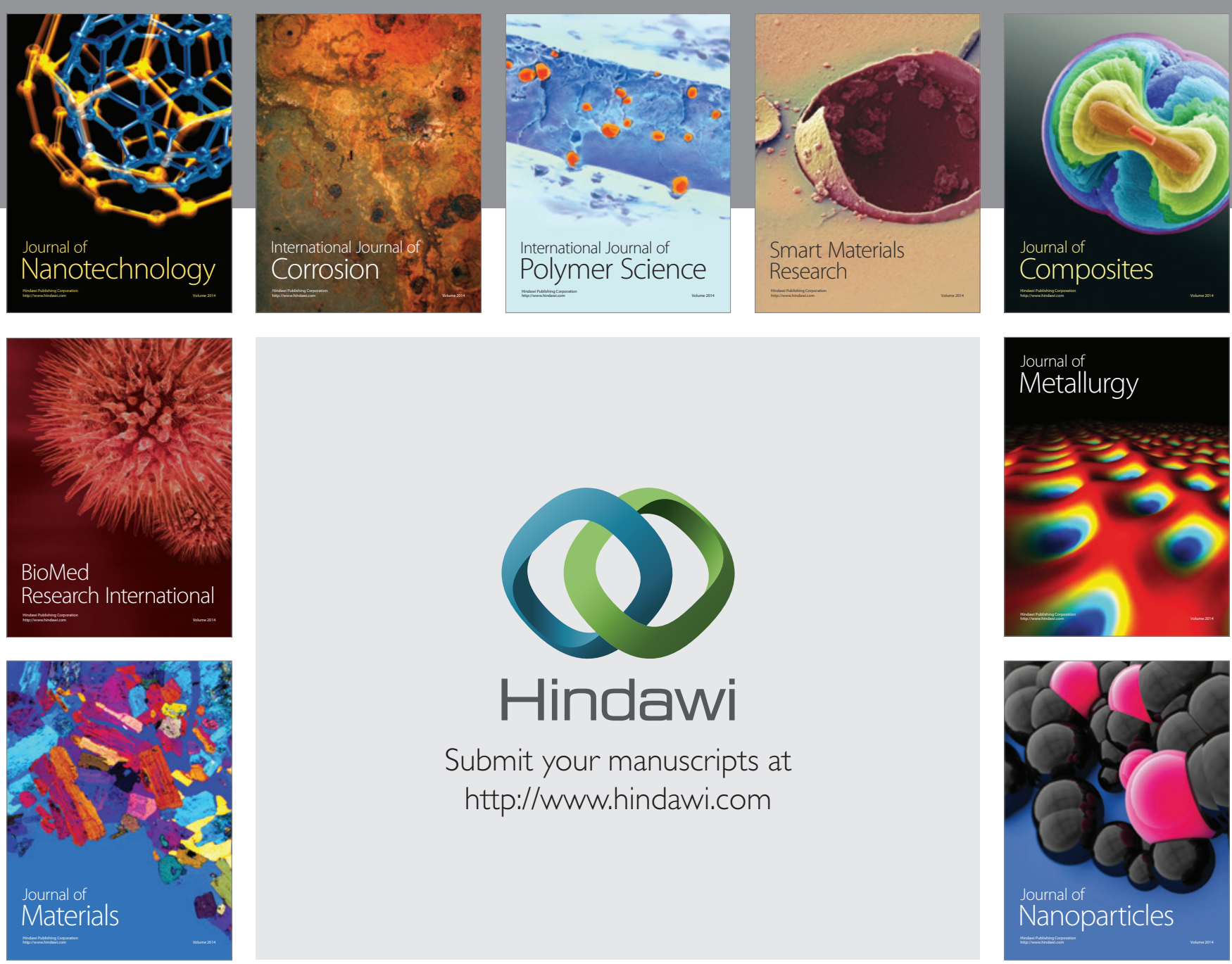

Submit your manuscripts at http://www.hindawi.com
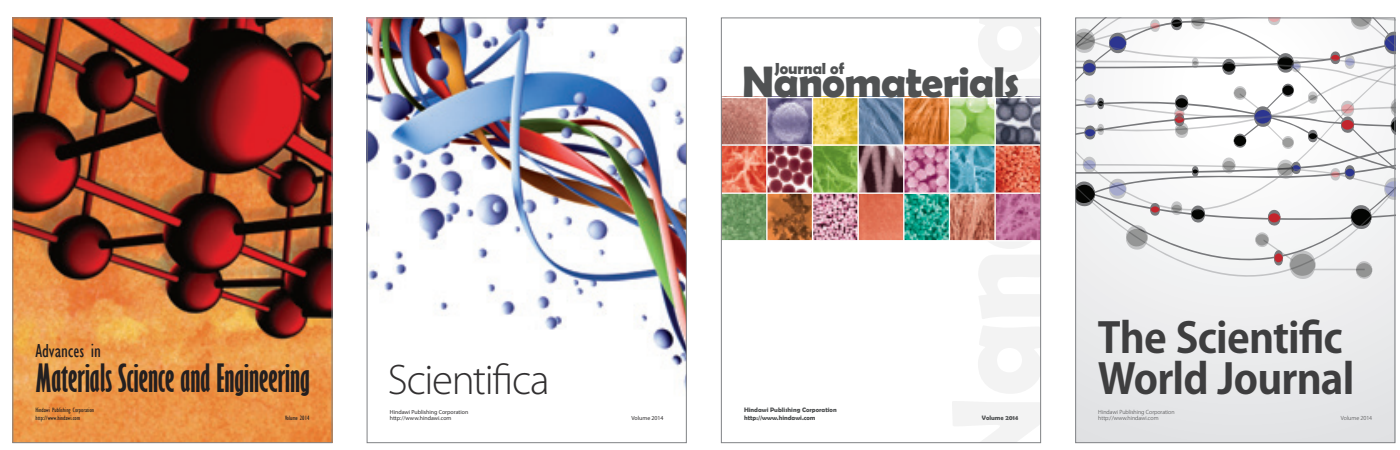

\section{The Scientific World Journal}
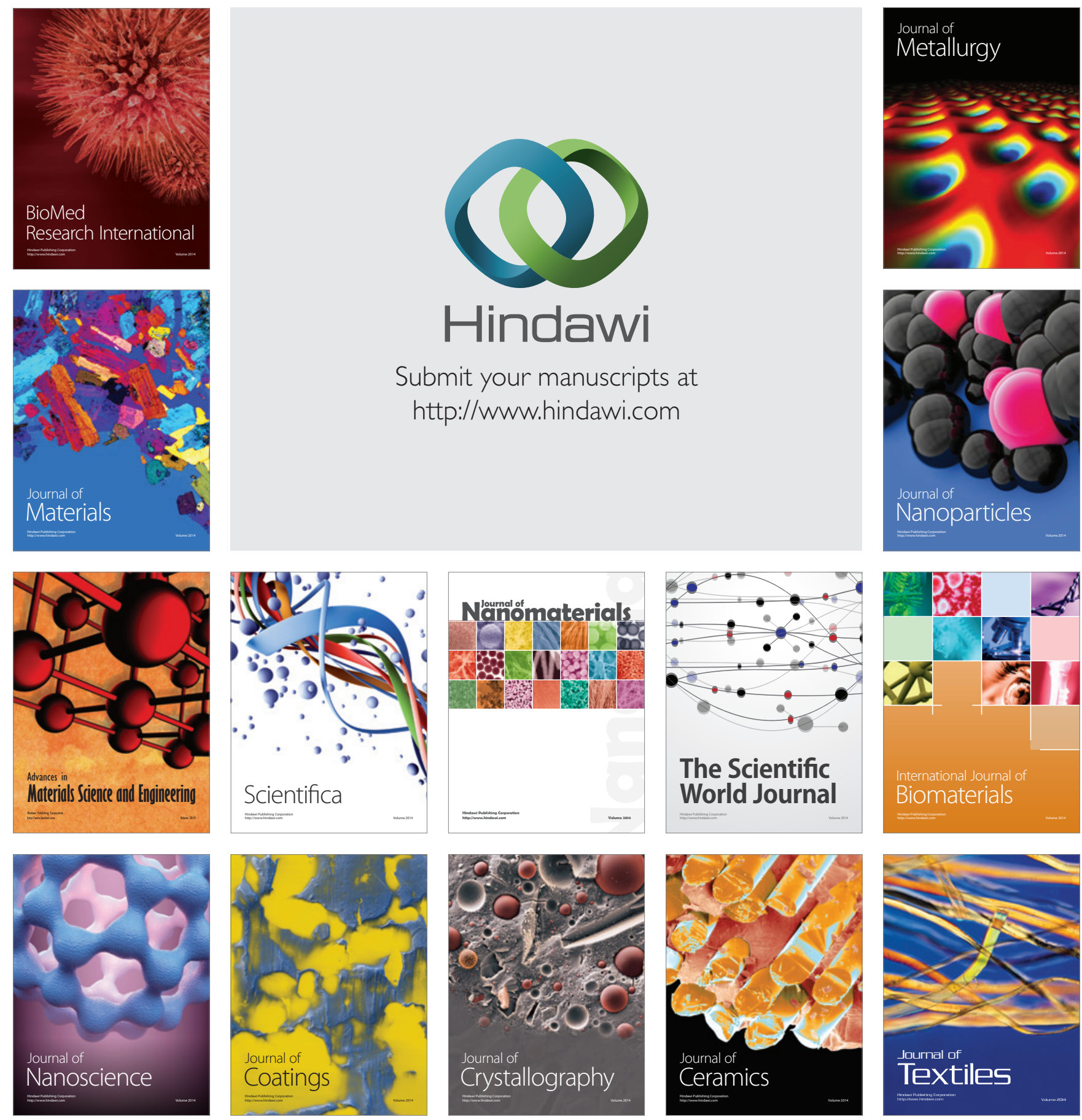